\title{
EXPER SIM: Review and update
}

\author{
GARY B. FORBACH \\ Washburn University, Topeka, Kansas 66621
}

\begin{abstract}
EXPER SIM (experimental simulation) is a pedagogical approach that facilitates learning the methods and principles of scientific research via simulation of experiments. A review of the EXPER SIM literature examines its educational potential and advantages, some presently available supervisor systems required for computer use, and evaluation of the method. Several updated sources of EXPER SIM material and programs are identified.
\end{abstract}

Main (1972) has observed that one of the most timeconsuming aspects of the traditional undergraduate psychology laboratory class is data collection. She contends that much of the time spent running subjects could be spent more profitably in some other pursuit and has therefore proposed a unique pedagogical framework in which to implement undergraduate science training. The procedure retains essential features of the traditional experimental approach and strengthens some shortcomings by relying primarily on simulated data. While this plan eliminates a great deal of data collection and hence some direct, firsthand laboratory experience, experience is not completely deleted. Instead, it is reduced and postponed until a working understanding of research methodology has been developed and the student is more likely to place the experience of running subjects in proper perspective.

\section{EXPER SIM PEDAGOGY}

Briefly, the pedagogy requires that a teacher represent a particular phenomenon in terms of precise, known (or assumed), mathematical or logical relationships between independent and dependent variables (a model). The student then formulates hypotheses and tests their adequacy by evaluating simulated data generated by a model. A computer is usually used to economically generate simulated data that are realistic and meaningfully interpretable. While the simulation model does reduce data collection time drastically, its primary purpose is to facilitate achievement of a significant educational opportunity, simulation of the scientific community by a laboratory class. This simulated scientific community often includes research proposals, grants, colloquia, journals, research budgets, and conventions. Papers written by class members and their predecessors provide a literature, and competing

Requests for reprints or information should be directed to Dr. Gary B. Forbach, Department of Psychology, Washburn University, Topeka, Kansas 66621. The work reported in this paper was partially funded by a grant from the Exxon Education Foundation's IMPACT program, June 15, 1977, to August 31, 1978. theories may be developed to account for the simulated evidence. Existing empirical evidence may also be made available at the instructor's option.

Student involvement with EXPER SIM may proceed at one or more levels of complexity. Ruggiero (1977), Main (Note 1), and Main, Stout, and Rajecki (Note 2) have suggested four possible modes of implementation. The first mode allows the student to manipulate a known set of independent variables and encourages the design of a comprehensive research program to define and explain phenomena. The second mode allows revelation of only a subset of the variables relevant for defining a model and then requires the student to operationalize and quantify the remainder. Mode 3 involves the student in modification of models investigated previously or in the development of new models. Mode 4 implementation encourages the student to evaluate the adequacy of a Mode 3 simulation model and to reconcile simulated data with empirical data collected by the student in an experiment.

The flexibility and versatility of the simulation approach is reflected in the following sample of topics translated into EXPER SIM models appropriate for use in psychology: imprinting, etiology of schizophrenia, motivation in routine tasks, and psychopharmacology (Main \& Head, 1971); social facilitation and electrical stimulation of the brain (Main \& Halstead-Nussloch, Note 3); fear and sex, obesity, selective attention, and the tip-of-the-tongue phenomenon (Thurmond \& Cromer, 1972); classical conditioning (Mink \& Nussloch, Note 4); group risky shift behavior (Shure, Malamuth, \& Johnston, Note 5); desensitization, distribution of practice, concept formation, and the serial position effect (Kissler, 1974); rat behavior in a T maze, including the effects of paradoxical punishment (Spelt, 1975); and transfer of training in verbal paired associate learning (Forbach, Note 6). Although the majority of such simulation models have been developed by psychologists, several have been developed and used successfully in other disciplines, including sociology, political science, physics, biology, chemistry, and engineering (Forbach, Note 6; Main, Williamson, \& Zinn, Note 7). 


\section{SUPERVISOR SYSTEMS}

A major problem associated with the EXPER SIM approach is the lack of widespread, well developed computer language skills in student populations. Therefore, several EXPER SIM originators developed simulation supervisor programs responsible for all input/output between the student and the model. Student input typically consists of meaningful key words or simple statements that approximate English. The simple supervisor syntax can be quickly mastered by consulting a lab manual. The supervisor edits and corrects many input errors, or else it prints an appropriate error message. The student therefore begins formulating, testing, and evaluating hypotheses without a substantial previous investment of time in learning how to program.

The first supervisors were designed to facilitate communication between the model and a student user with no programming skills. However, some degree of programming sophistication was required to transport a program to a new installation, to add new models to existing libraries, or even to make minor modifications in existing models. To facilitate such changes, several systems incorporated a model-building segment that allows models to be developed or modified quickly without the user first learning a programming language. Written in FORTRAN IV, one of the most widely used systems is the Michigan Experimental Simulation Supervisor (MESS), reported by Stout $(1974,1975)$. Extensive documentation and lab manuals have considerably facilitated transportability of MESS. The BASIC language Louisville Experimental Simulation System (LESS), detailed by Cromer $(1973,1974)$ and by Thurmond and Cromer (1975), as well as its progeny, the Wabash Research Investigation Simulation Teacher (WRIST), written in BASIC-PLUS, have also been tested extensively. A WRIST user's manual (Spelt, 1975) provides extensive detail on its various capabilities. Kissler (1974) described the Washington State University EXPER SIM system called LABSIM (in FORTRAN and PL/I versions), and Shure and Brainerd (1975) reported the implementation of a FORTRAN language EXPER SIM system at the University of California at Los Angeles, which has been integrated into their other computer-oriented laboratories. Also, a University of Kansas FORTRAN language supervisor called KUSIM has been described by Hallenbeck and Welch (1974). These systems have operated on a wide variety of computers, indicating considerable machine independence (Main et al., Note 7).

Until recently, smaller computers $(60-90 \mathrm{~K})$ lacking a BASIC compiler were unable to easily implement an existing EXPER SIM supervisor, since the transportable FORTRAN supervisors require $90 \mathrm{~K}$ or more core storage. However, there has been some demonstrated success in scaling down MESS for use on smaller machines. Nelson (Note 8) modified MESS 3-SC to operate imprinting and statistical models on a $64 \mathrm{~K}$ GA 1830 computer. An extension of her work produced a supervisor called WISER, which is currently in use on an IBM 360/30 (65K) computer. Five previously developed EXPER SIM models (IMPRINT, TMAZE, MAC, UNIV, and MOTIV) are supplemented by two locally written models. WISER is currently limited to batch mode and printed output only. However, WISER requires less than two-thirds the core storage required by MESS 3-SC (55K vs. 90K) yet provides virtually all MESS 3-SC options and services, such as descriptive statistics, replications, repeated-measures designs, output format options, multiple dependent variables, and up to five-factor experiments defined with only five input cards (Forbach, Note 9). WISER operates substantially slower than does MESS 3-SC, and it provides less comprehensive editing, necessitating slightly more rigid student input conventions. The success of WISER is significant primarily because it demonstrates the feasibility of modifying large supervisors (such as MESS) for use on mini- or microcomputers, many of which now have memories considerably larger than $64 \mathrm{~K}$. A modest investment in development of supervisors for these small computers could therefore make the EXPER SIM approach available to many more potential users.

\section{EVALUATION}

Nearly a decade of EXPER SIM development and evaluation has proceeded since Johnson's (1971) DATACALL game was conceived and implemented. A consistent emphasis on evaluating EXPER SIM is reflected in a large body of information. These data enable several conclusions regarding EXPER SIM use: Considerable time is conserved, yielding more efficient use of laboratory time; there is a significant reduction in cost per experiment; students have access to experiments that would not otherwise be possible because of insufficient funds, equipment problems, or ethical considerations; student interest increases; difficulty and complexity of the problem may be adjusted to match the level of the students (e.g., four-way interactions attenuated for introductory work, then introduced for advanced students); more efficient supervision of introductory students is enabled since the instructor has more control over the model than the real world; and, finally, the simulation of the scientific community by a laboratory class requires students to deal explicitly with the necessary features of good research by encouraging and rewarding integrated research programs more than single, isolated experiments.

In addition to evaluation results reported in previously cited work, other investigators have reported positive results (Johnson, 1974; Nussloch, Kaplan, \& Main, 1974; Spelt \& Schafer, 1976). Also, the final reports submitted by 60 recipients of EXPER SIM implementation funds have contributed evidence of the efficacy of EXPER SIM (Johnson, Note 10). While no 
evidence has been reported indicating that students using EXPER SIM learn less than students in a traditional class, neither is there much rigorous evidence that supports the contention that students learn more when using EXPER SIM. In fact, rarely has this issue been dealt with directly. Neither has there been a comprehensive attempt to determine the types of skills learned by students using EXPER SIM. Thorny issues such as training objectives, measurement criteria, and teaching ethics exist as barriers to this type of evaluation, and hence evaluation has typically proceeded in an indirect fashion.

In summary, two major evaluation generalizations seem appropriate. First, in addition to pedagogical advantages, there are several demonstrable benefits (finances, time conservation, student in terest, flexibility, etc.) derived from the incorporation of EXPER SIM into the curricula. Add to these the availability of widely tested software and plummeting hardware costs, and there are compelling reasons for teachers to consider EXPER SIM. Second, EXPER SIM users must now make a concerted effort to develop rigorous methods to evaluate exactly what and how much is learned using EXPER SIM.

\section{EXPER SIM INFORMATION SOURCES}

\section{WRIST}

WRIST (in BASIC-PLUS) is an extensively tested, easily transported supervisor designed to operate on an RSTS or RSTS/E system with a minimum of $8 \mathrm{~K}$ of core per user. A detailed instructor's manual facilitates implementation of available models and explains the General Model Builder for new model development. A student manual provides a short scenario for each model and explains how to simulate experiments. Several years of experience in transporting WRIST have helped to streamline the process and to eliminate many potential implementation bugs. For information, contact Dr. Philip Spelt, Psychology Department, Wabash College, Crawfordsville, Indiana 47933.

\section{MESS}

Readers interested in EXPER SIM who have access to a medium- to large-scale computer are referred to Main and Stout (1978). Reviewed and tested, and easily transported, versions of two MESS models complete with all implementation documentation and student manuals are available through CONDUIT. (CONDUIT is an organization funded by the National Science Foundation to promote review, testing, standardization, and dissemination of educational computing materials.) The two models presently available, IMPRINT (PSY 192) and SCHIZ (PSY 194), are student user oriented only and cannot easily be modified.

Also available through CONDUIT is a tested, transportable "Model Builder's Kit." It includes the student supervisor, library subroutines, the model writer program, and a detailed manual explaining the model development process. The programmer's version, EXPER SIM (MESS) (MUL032), allows use of the two tested models or allows development of new models by the user. CONDUIT will also serve as a clearinghouse for newly developed models that authors wish to disseminate. All programs are written in transferable ANSI FORTRAN for batch or interactive use.

For ordering information, write to CONDUIT, University of Iowa, 100 LCM, Iowa City, Iowa 52242. Also, ask for Pipeline, a CONDUIT publication devoted to computer applications in education.

\section{WISER}

If none of the supervisors above is feasible, an instructor interested in EXPER SIM may wish to consider WISER. Minimum hardware configuration includes one high-speed disk drive, a CPU allowing a 55K partition for program execution, plus enough additional core for the local operating system. System software must include overlay routines. The author will, on request, provide without charge a package of information explaining WISER use, including discussion of likely implementation bottlenecks and a comparison of the capabilities of WISER and MESS 3-SC.

For a handling fee of $\$ 20$, a complete source deck and listing of WISER and all support programs and models, a programmer's guide, and a revised user's manual are available from the author. If a magnetictape copy is desired, the author will supply programs on user-supplied tape $(2,400 \mathrm{ft}, 1,600 \mathrm{bpi}$, nine track), along with listings and a revised user's manual, for a $\$ 20$ handling fee.

\section{REFERENCE NOTES}

1. Main, D. B. The laboratory class as a simulated scientific community. Paper presented to the National Gaming Council, Baltimore, Maryland, 1972.

2. Main, D. B., Stout, R., \& Rajecki, D. W. A pedagogical schema for the development and use of computer simulation technology. Paper presented at the Combined 12th Annual Symposium of the National Gaming Council and 4th Annual Conference of the International Simulation and Gaming Association, Gaithersburg, North Carolina, 1973.

3. Main, D. B., \& Halstead-Nussloch, R. (Eds.). Research design and methodology through computer simulation. Xerox Individualized Publishing Program, 1975.

4. Mink, W., \& Nussloch, R. PAVCO: A computer simulation on Pavlovian conditioning. Paper presented to the American Psychological Association, Washington, D.C., September 1971.

5. Shure, G. H., Malamuth, N. M., \& Johnston, S. A. A computer simulation of group risky shift for teaching undergraduate research methods. Paper presented at the American Psychological Association, New Orleans, Louisiana, 1974. (Also CCBS Document CCBS-P-16, University of California, Los Angeles, 1974.)

6. Forbach, G. B. WISER: Development history of the Washburn Instructional Simulation of Experimental Research version of MESS. Unpublished final grant report to Exxon Education Foundation, 1978. (Available from Gary B. Forbach, Department of Psychology, Washburn University, Topeka, Kansas 66621.)

7. Main, D. B., Williamson, A., \& Zinn, K. L. The dissemination of EXPER SIM: A case history of sharing computer programs in college teaching. Unpublished manuscript, 1975. (Available 
from Dana Main, West Virginia College of Graduate Studies, Beckley Center, Beckley, West Virginia 25801.)

8. Nelson, L. Personal communication (including supervisor code for Lindenwood Colleges version of MESS), September 1977.

9. Forbach, G. B. WISER: An EXPER SIM supervisor compared with its predecessor, MESS 3-SC. Unpublished progress report, Washburn University, 1978. (Available from Gary B. Forbach, Department of Psychology, Washburn University, Topeka, Kansas 66621.)

10. Johnson, R. Telephone conversation, January 15, 1979. (For additional information, contact Richard Johnson, Research Director, Exxon Education Foundation, 11 West 49th Street, New York, New York 10020.)

\section{REFERENCES}

Cromer, A. O. Teaching experimental psychology with on-line computers. Behavior Research Methods \& Instrumentation, 1973, 5, 195-197.

Cromer, A. O. Teaching research theory and application through on-line simulation. Behavior Research Methods \& Instrumentation, 1974, 6, 126-127.

Hallenbeck, C. E., \& Welch, R. B. Generalizing the problem definition step in the computer simulation of factorial experiments. Behavior Research Methods \& Instrumentation, 1974, 6, 111-121.

Johnson, R. DATACALL. A computer-based simulation game for teaching strategy in scientific research. In Proceedings of the conference on computers in the undergraduate curricula. Hanover, N.H: Dartmouth College, 1971.

Johnson, R. Instructional simulation: The interface with the student. Behavior Research Methods \& Instrumentation, 1974, 6, 128-130.

KisSLER, G. R. Evaluation of computer-based laboratory simulation models to teach scientific research strategies. Behavior Research Methods \& Instrumentation, 1974, 6, 124-126.

Main, D. B. Toward a future-oriented curriculum. American Psychologist, 1972, 27, 245-248.

Main, D. B., \& Head, S. Computer simulation in the elementary psychology laboratory. In Proceedings of the conference on computers in the undergraduate curricula. Hanover, N.H: Dartmouth College, 1971.

MaIn, D. B., \& Stout, R. EXPER SIM: A computer-based experimental simulation system. Pipeline, 1978, 3, 16-23.

Nussloch, R., Kaplan, R. J., \& Main, D. B. Casual critique or active arguments? In Proceedings of the conference on computers in the undergraduate curricula. Pullman, Wash: Washington State University, 1974.

Ruggiero, F. An overview of the development of computer modeling for instructional and research purposes. Behavior Research Methods \& Instrumentation, 1977, 9, 76-80.

Shure, G. H., \& Brainerd, K. MODELR-Model building and model modification for instruction. Behavior Research Methods \& Instrumentation, 1975, 7, 221-225.

SPElt, P. F. (Ed.). WRIST: Wabash research investigation simulation teacher student's guide. Crawfordsville, Ind: Wabash College, 1975.

Spelt, P. F., \& Schafer, S. R. The use and evaluation of EXPER SIM: What does it teach and how should it be evaluated? In Proceedings of the conference on computers in the undergraduate curricula. Binghamton, N.Y: State University of New York at Binghamton, 1976.

STout, R. Modeling and the Michigan experimental simulation supervisor: An overview and some prospects. Behavior Research Methods \& Instrumentation, 1974, 6, 121-123.

STout, R. Modeling on the simulation writer interactive program. Behavior Research Methods \& Instrumentation, 1975, 7, 226228.

Thurmond, J. B., \& Cromer, A. O. Toward the optimal use of computer simulations in teaching scientific research strategy. In Proceedings of the conference on computers in the undergraduate curricula. Atlanta, Ga: Georgia Institute of Technology, 1972.

Thurmond, J. B., \& Cromer, A. O. Models and modeling with the Louisville experiment simulation system (LESS). Behavior Research Methods \& Instrumentation, 1975, 7, 229-232.

(Accepted for publication July 26, 1979.) 